\title{
HONOR OF HONORARIUM
}

\author{
Prof. L. Floor
}

\section{Inleiding}

IN die geskiedenis van die kerk vind ons verskillende voorbeelde wat daar op wys dat nie elkeen kon saamstem met die praktyk om predikante van 'n traktement te voorsien nie. Met name wanneer dit sendelinge betref dan mag daar nie so iets soos 'n vaste lewensonderhoud aan hulle gegee word nie. Dit is byvoorbeeld bekend dat die London Missionary Society sendelinge na Suid-Afrika gestuur het wat self in hulle lewensonderhoud moes voorsien.'

Om hierdie standpunt te handhaaf is dikwels 'n beroep gedoen op die woorde van Jesus in die Evangelie wat Hy uitgespreek het by die uitsending van die sewentig: ,Moenie vir julle goud of silwer of koper in julle beurse aanskaf nie; geen reissak vir die pad of twee kleidingstukke of skoene of 'n stok nie, want die arbeider is sy voedsel werd" (Matt. 10:9,10).

Iemand wat 'n traktement ontvang word soms met 'n beroep op die Didache nie as 'n ware dienaar van God aanvaar nie.2

Aan die ander kant het Paulus in die eerste Brief aan die Korinthiërs tog 'n duidelike reël neergelê dat die wat die Evangelie verkondig ook van die Evangelie moet lewe (1 Kor. 9:14).

In die diskussie oor hierdie saak speel 1 Tim. 5:17, 18 'n groot rol. Daar skrywe Paulus vir Timótheüs dat die ouderlinge wat goed regeer dubbele eer waardig geag moet word, veral die wat arbei in woord en leer. Paulus motiveer dan sy stelling met 'n sitaat uit die O.T. en met 'n logion van Jesus.

Die vraag wat hier opduik is: wat moet ons verstaan onder ,dubbele eer'? Word hiermee eerbetoon of eerbewys bedoel soos die formulier vir die bevestiging van ouderlinge en diakens dit stel? Of moet ons hier dink aan 'n uitkering, 'n traktement? Honor of honorarium, dit is die probleem.

Wanneer ons 'n ondersoek gaan instel na die regte verklaring van hierdie woorde van Paulus dan is daar heelwat vrae wat gestel moet word.

1. wat word bedoel met ouderlinge?

2 . wat is 'n ouderling wat goed regeer?

3. wat is 'n goed regerende ouderling wat arbei in woord en leer?

4. wat word bedoel met, dubbele' in die formulering ,dubbele' eer?

5. wat is die betekenis van die Skrifbewys?

6. hoe skakel 'n logion van Jesus met 'n uitspraak uit die O.T.?

7. wat is die presiese inhoud van die begrip ,eer'?

\section{Die presbiter in die Pastorale Briewe}

Om die vraag na die regte betekenis van die uitdrukking, dubbele' 
eer te kan oplos, moet eers nagegaan word wat in die Pastorale Briewe (in die vervolg as P.B. aangedui) met die woord presbiter bedoel word. J. Jeremias sien in die begrip presbiter nie 'n ampsaanduiding nie maar ' $n$ wat hy noem ,Alterbezeichnung'. ${ }^{3}$ Ouderlinge in die P.B. is dus volgens Jeremias oudstes of ou manne. Hoewel dit altyd die moeite loon om na Jeremias te luister, lyk dit tog baie onaanneemlik om in hierdie perikoop waar dit oor ampsdraers handel die woord $\pi \rho \varepsilon \beta v \tau \varepsilon \rho \circ$ in biologiese sin en nie in amptelike sin op te vat nie. In $5: 1$ is die woord $\pi \rho \varepsilon \sigma \beta v \tau \varepsilon \rho o$ stellig 'n ,Alterbezeich-

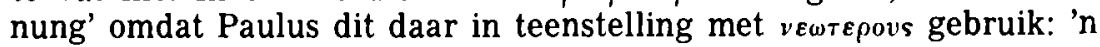
bejaarde man teenoor jongeres.

Maar in 5:17 skrywe Paulus oor presbiteroi wat goed regeer. Die werkwoord $\pi \rho \circ \varepsilon \sigma \tau \omega \tau \varepsilon s$, perf. part. van $\pi \rho \circ \iota \sigma \tau \mu \alpha \alpha$ het soos in Rom. $12: 8$ en 1 Thess: $5: 12$ 'n tegniese, amptelike betekenis, ${ }^{4}$ hoewel die nie-tegniese gebruik van hierdie werkwoord ook by Paulus voorkom (vgl. 1 Tim. $3: 4,5,12$ en Titus $3: 8,14$ ).

Dit is nie moontlik om hier die hele probleem van die identifikasie of non-identifikasie van die presbiter en die episkopos te behandel nie. ${ }^{5}$ As konklusie kan net genoem word dat in die P.B. die beide begrippe presbiter en episkopos promiscue gebruik word. Die presbiters van 1 Tim. 5:17 verskil nie wesentlik van die episkopoi van 1 Tim. 3:5 nie. In die P.B. word dan ook die taak van die presbiter/episkopos met dieselfde woorde omskryf soos ons dit vind in die gemeentebriewe van Paulus. Hierby moet dan veral gelet word op die gebruik van die woord prostenai. ${ }^{6}$

Dit is opvallend dat Timotheüs in die kerk te Efese reeds 'n kollege van presbiters gevind het. Dit moet ten minste ons konklusie wees wanneer ons 1 Tim. 4:14 vertaal soos die Engelse Bybel dit doen: "with the laying on of the hands of the presbytery". Die groot vraag is hier of ons $\pi \rho \varepsilon \sigma \beta v \tau \varepsilon \rho \iota$ moet $^{\circ}$ beskou as 'n gen. finalis: handoplegging met die oog op die ouderlingskap (so: D. Daube en J. Jeremias) of as 'n gen. subj.: handoplegging van die gesamentlike ouderlinge (so: G. Bornkamm in Th.W.B., VI, p. 666). Die woord $\pi \rho \varepsilon \sigma \beta v \tau \varepsilon \rho \iota v$ laat hom moeilik kwalifiseer as 'n finale genitief. Dan sou die woord $\pi \rho \varepsilon \sigma \beta v \tau \varepsilon \rho o v$ eerder van pas gewees het, maar die lesing $\pi \rho \varepsilon \sigma \beta v т \varepsilon \rho 0 v$ met die lidwoord rov is weinig aanneemlik en het ook 'n swak teksgetuienis.'

Ook al kies ons vir die lesing $\pi \rho \varepsilon \sigma \beta v \tau \varepsilon \rho \iota v$ mag dit ons nie verlei tot 'n goedkoop harmonisasie-poging van 1 Tim. 4:14 met 2 Tim. 1:6 waar gespreek word van handoplegging by Timotheüs deur Paulus nie. Paulus word dan gepromoveer tot voorsitter van die raad van presbiters. Dit is nie reg nie, want in die eerste teks word Paulus nie genoem nie en in die tweede teks is daar nie sprake van 'n kollege nie. 'n Tweede argument teen die gen. finalis is die feit dat Paulus in die P.B. Timótheüs nêrens aandui as 'n presbiter nie. Timotheüs is die ad hoc ,apostoliese gedelegeerde" deur die apostel aangedui as "my ware kind" (1 Tim. 1:2) of „my seun" (2 Tim. $2: 2$ ).

In die derde plek kan genoem word dat ten tye van Ignatius daar al sprake was van 'n presbyterium as vasstaande kollege van 
ouderlinge. ${ }^{8}$ Daar is dus sterk argumente om te aanvaar dat daar tydens Timótheüs se verblyf in Efese in die kerk reeds die instituut van presbyterium bestaan het, ' $n$ soort raad van presbiters. Dit behoef ons ook nie te verbaas nie wanneer ons daaraan dink dat in die Joodse sinagogale gemeenskap ook reeds so 'n raad van oudstes bestaan het. Hierdie raad het o.a. finansiële beheer uitgeoefen. ${ }^{9}$ Armversorging was ook aan hierdie raad toevertrou..$^{10}$

Wanneer ons vervolgens $1 \mathrm{Tim}$. 5:17 nader bekyk dan sal ons opmerk dat daar in die kollege van presbiters al so iets soos 'n „Functional specialization" was." Ons kan in ieder geval in 1 Tim. $5: 17$ drie - sommige sê self vier — groepe van ouderlinge onderskei:

a. presbiters;

b. presbiters wat leiding gee;

c. presbiters wat goed leiding gee;

d. presbiters wat arbei in woord en leer. ${ }^{12}$

$\mathrm{J}$. Reville is van oordeel dat die formulering, goed regeer' ( $\kappa \alpha \lambda \omega s)$ 'n aanduiding wil gee dat daar in die kerk te Efese ook ouderlinge was wat nie in ywer en toewyding uitgeblink het nie. ${ }^{13}$

Dit lyk vir my dat hier nie 'n diskriminerende teenstelling gemaak word nie. Miskien moet ons die verskil veel meer soek in die feit dat sommige presbiters ,full time" of altans 'n groot gedeelte van hul tyd aan die uitoefening van hul amp bestee het met as gevolg minder tyd vir eie arbeid en meer behoefte om deur die gemeente versorg te word.

Dit is m.i. die beste om te aanvaar dat die skrywer van die P.B. hier drie groepe van presbiters aandui: ouderlinge wat leiding neem, ouderlinge wat goed regeer en ouderlinge wat arbei in woord en leer.

Van die laaste groep word dan gesê dat hulle soos daar letterlik staan ,met moeite of met inspanning arbei' in woord en leer. Die

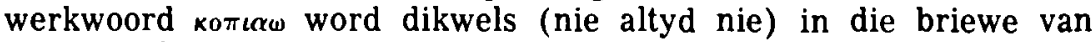
Paulus gebruik as 'n tegniese term vir ministeriële aktiwiteit.14

In die uitdrukking, in woord en leer' ontbreek sowel by $\lambda \circ \gamma_{\omega}$ as by $\delta \iota \delta \alpha \sigma \kappa \alpha \lambda \iota \alpha$ die bepalende lidwoord. Ons moet hier dan ook nie dink aan die Woord van God nie, maar die spreke van die woord, die prediking. Die woord $\delta \iota \delta \alpha \sigma \kappa \iota x \lambda \iota \alpha$ in sy verbinding met $\lambda$ o daarop dat dit hier gaan om 'n "Anleitung zu christlichem Leben", 15 om die etiese implikasies van die kerugma. Daar mag egter nie 'n teenstelling tussen ,woord' en ,leer' gemaak word nie. Die spesifieke van die ,leer' in onderskeiding van ,kerugma' lê nie soseer in die inhoud nie as wel in die vorm. ${ }^{16}$

Die vraag bly nog wie van die presbiters ,dubbele eer' moet ontvang. Is dit alleen diegene wat arbei in woord en leer of ook hulle wat goed regeer? Die woord ie $\mu \alpha \lambda \iota \sigma \tau \alpha$ wat ons kan vertaal

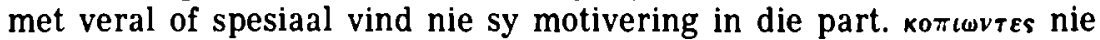
,alsof het de grotere toewijding was, die hun een bizonder recht op beloning gaf". ${ }^{17}$ Die nadruk val hier op die arbeid wat hulle verrig. Dit lyk of sowel die ouderlinge wat goed regeer as ook hulle wat 
arbei in woord en leer reg het op ,dubbele eer', terwyl die adverbium $\mu \alpha \lambda_{\iota \sigma \tau} \alpha$ dan vir ons wil sê dat dit besonderlik geld van hulle wat arbei in woord en leer.

\section{Dubbele eer}

By die uitdrukking ,eer' duik daar weer probleme op. Moet ons ,eer' opvat as eerbetoon, honor, of is met, eer' bedoel 'n materiële beloning, 'n honorarium? Daarby kom dan nog die vraag wat met ,dubbel' bedoel word. Moet ons die woord ,dubbel' in komparatiewe sin gebruik en so ja wat is dan die vergelykingsnorm of moet ons dit in ' $n$ meer absolute betekenis aanwend?

Wanneer ons die verskillende kommentare raadpleeg dan vind ons uit dat daar aan die woord $\tau \iota \mu \eta$ drie verklarings gegee word: eer, lewensonderhoud, eer en lewensonderhoud. 'n Sterk voorstander van $\tau \iota \mu \eta$ as ,eer' is W. Michaelis. Aangesien 1 Tim. 5:18 as Skrifbewys vir die voorgaande teks tog wel sterk wys in die rigting van, honorarium' los Michaelis die probleem op 'n eenvoudige manier op deur vs. 18 tot 'n glosse te verklaar. ${ }^{18}$ A. Schlatter doen presies dieselfde. ${ }^{19}$ Die gedagte van $\tau \iota \mu \eta$ as alleen eer word ook voorgestaan deur Tertullianus, Bengel en Schlatter, terwyl elkeen tog weer aan ,eer' 'n ander betekenis gee. Tertullianus dink by eer aan hemelse en aardse eer, eer as broeders en regeerders, Bengel spreek van eer „ob presbyteratum et ob munus”, dus eer ter wille van hul ouderdom en hul amp, terwyl Schlatter eer beskou as "Hochachtung'.20 'n Sterk argument vir hierdie verklaring is wel die gebruik van die

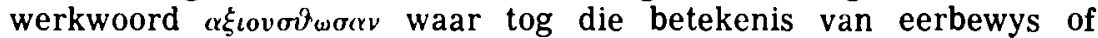
waardig geag word in tot uitdrukking kom..$^{21}$

'n Tweede groep eksegete verklaar $\tau \iota \mu \eta$ as lewensonderhoud (o.a. Moffat, Williams, White in Expositor's Greek Testament). Die derde groep dink by $\tau \iota \mu \eta$ aan eer én lewensonderhoud (Chrysostomos, Calvyn, Locke, Bouma, Ridderbos, La Glose, St. Thomas, Cajetanus, Von Soden, Falconer en Jeremias). Myns insiens is dit die beste om by die woord $\tau \iota \mu \eta$ sowel aan eer as ook aan lewensonderhoud te dink. Ons kan die volgende argumente aanvoer:

1. In klassieke Grieks is $\tau \iota \mu \eta$ sterk materieel georiënteer. Ons vind dit byvoorbeeld in die werke van Homerus. Die eer van Achilles bestaan in ' $n$ magdom van geskenke wat hy ontvang.2

2. In die hellenistiese Jodendom het $\tau \iota \mu \eta$ ook die betekenis van 'n geldprys, kosbaarheid (Sirach $45: 12$ ), belasting (1 Makk. 10:29).

3. In die N.T. gaan $\tau \iota \mu \eta$ dikwels saam met $\delta$ o $\xi_{\alpha}$ (bv. Hebr. $2: 7$; $3: 3 ; 1$ Tim. $1: 17$; Openb. $21: 26$ ). Juis in sy verbinding met $\delta \circ \xi \alpha$ kan $\tau \iota \mu \eta$ 'n materiële betekenis hê. ${ }^{23}$ "Le premier terme $(\delta \circ \xi \alpha)$ insiste un peu plus sur la dignité supernaturelle, tandis que l'autre $(\tau i \mu \eta)$ rapelle plutôt l'autorité sur tous les êtres. ${ }^{24}$

4. Die konteks dwing wel sterk in die rigting van die materiële:

a. Die opvallende ooreenkoms tussen 1 Tim. 5:17 en 1 Tim. 5:3 waar dit handel oor die versorging van die weduwees. Ons kan 'n hele lys van kroongetuies vir hierdie opvatting noem bv. die Griekse vaders, Ambrosiaster, Scott, Padovani, Calvyn en Lock. Die laaste 
argumenteer sy standpunt met 'n verwysing na die Constitutiones apostolicae. ${ }^{25}$ By hierdie verklaring moet ons $\delta \iota \pi \lambda \eta s$ as 'n kwantitatiewe adjektief beskou en dus uitgaan van die komparatiewe betekenis van hierdie vorm. Nou is daar inderdaad in die literatuur verskillende voorbeelde van ' $n$ dubbele uitbetaling in letterlike sin. Dubbel soldy is byvoorbeeld gegee aan besonder toegewyde soldate wat hulle in die oorlog onderskei het. Ook is daar ' $n$ teks waarin vermeld word van 'n profeet wat van die keiser 'n $\delta \iota \pi \lambda \alpha \sigma \psi^{\prime} \omega v^{\prime} \iota \alpha$ ontvang het vir bewese dienste aan sy vors. ${ }^{26}$

b. Die sterkste argument om by $\tau \iota \mu \eta$ ook aan materiële versorging te dink vind ons in vs. 18 wat deur Michaelis soos ons reeds gehoor het as 'n latere addisie verwerp is. Paulus wys op die versorging van toegewyde presbiters met ' $\mathrm{n}$ beroep op die Skrif $\mathrm{nl}$. Deut. 25:4 wat deur die apostel in 1 Kor. 9:9 op dieselfde wyse aangehaal word. Hierdie uitspraak gee nie so baie probleme nie. Die LXX gee hierdie woorde in ' $n$ ander volgorde $\left(\begin{array}{llll}3 & 4 & 1 & 2\end{array}\right)$, maar die volgorde van die LXX vind ons ook miskien deur korreksie in ander handskrifte. Toepassing van hierdie reël vind ons ook by die rabbyne. ${ }^{7}$ Of Paulus hier wil allegoriseer soos J. Jeremias oordeel, moet wel betwyfel word. ${ }^{28}$ Paulus hou vas aan die letterlike betekenis van die woorde uit die O.T. Meer probleme is daar egter met die tweede aanhaling van die skrywe. Hy siteer 'n logion van Jesus (Matt. 10:10; Luk. 10:7) en dui daardie logion dan aan as 'n Skrifwoord, ten minste as ons die voegwoord ker so sterk moet laai dat dit ook hierdie logion aan $\gamma \rho \alpha \psi \eta$ koppel. Sowel C. Bouma as W. Michaelis erken dat deur die aanwending van $k \alpha \iota$ die tweede aanhaling nie anders as onder die woorde: want die Skrif sê, gerangskik kan word nie. Dit is vir Michaelis 'n argument om vs. 18 as 'n glosse op te vat en vir Bouma om aan te neem dat die evangelie volgens Lukas in die dae van die skrywer van die 1 Tim.brief reeds as kanoniek beskou is. ${ }^{29}$

Nou is dit wel opvallend dat die skrywer van $1 \mathrm{Tim}$. hierdie logion in ooreenstemming met Lukas aanhaal (10:7) en nie met

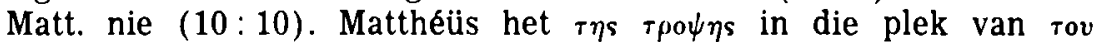
$\mu \iota \sigma v^{\circ}$. Wanneer ons aanvaar dat Paulus die P.B. geskryf het dan behoef die ooreenstemming tussen 1 Tim. 5:18 en Luk. 10:7 ons nie te verbaas nie, aangesien Lukas die reisgenoot van Paulus was.

Daar is ook die moontlikheid dat die skrywer van die P.B. hierdie logion via die mondelinge oorlewering of via die tradisie ontvang het. C. Spicq kwalifiseer hierdie woord as „la plus ancienne citation d'une parole évangélique comme "Ecriture" ",30 terwyl Lock spreek van "the earliest instance of the Lord's words being quoted as "Scripture" "." Miskien staan ons hier op die grens van die oorgang van die mondelinge na die skriftelike tradisie. Wanneer dit so sou wees dan kan daar miskien ook 'n argument aan ontleen word vir 'n latere datering van 1 Tim., 'n opvatting wat egter deur $\mathbf{C}$. Bouma sterk bestry word. ${ }^{32}$

Dit lê dus die meeste vir die hand om by ,eer' te dink aan honorarium. Dit is 'n begrip wat gelyk met die materiële ook die ,honor' insluit. Die klem val inderdaad op respek en erkenning wat dan ge- 
stalte kry in die vorm van lewensonderhoud. Die eintlike crux bly $\delta \iota \pi \lambda \eta s$. Wil ons dit in komparatiewe sin opvat dan is die gedagte van Lock en Calvyn dat die ouderlinge twee maal so veel moet ontvang as die weduwees nog nie so dwaas nie.

Ons kan egter $\delta \iota \pi \lambda \eta s$ ook in absolute sin opvat soos byvoorbeeld H. N. Ridderbos voorstel met 'n verwysing na Spicq wat weer kom met 'n aanhaling van Chrysostomus. ${ }^{33}$ Dit bly egter 'n vraag of daar dan wel voldoende reg gedoen word aan die letterlike betekenis van $\delta \iota \pi \lambda \eta s$ waar tog duidelik die gedagte in skuil van dubbel of twee keer. Daarom sou ek liewer wou voorstel om $\delta \iota \pi \lambda \eta$ s te beskou as twee keer soveel as die weduwees of as ander presbiters. Hoewel dit maar baie moeilik is om 'n verstandige woord oor finansiële sake en hoe hulle in die ou kerk behartig is te sê, wil ek dit tog waag om hieroor 'n paar opmerkings te maak.

Waarskynlik was daar in die ou kerk 'n presbyterium wat bepaalde vorme van ooreenkoms met die Joodse Raad vertoon het. Aan hierdie Raad van oudstes was sowel die finansiële beheer as ook armversorging toevertrou. K. L. Schmidt het in 'n feesbundel vir A. Deismann aangetoon dat ook in die ou kerk diakonie en beheer van gemeente gelde na alle waarskynlikheid nog nie van mekaar geskei was nie..$^{34}$ Dit is dus nie heeltemal onmoontlik nie dat sowel ,lerende' en ,katkiserende' ouderlinge saam met die weduwees van die gemeente gereeld 'n uitkering uit die kas van gemeentefondse gekry het en dat dan die presbiters die dubbele bedrag van wat aan weduwees gegee is, ontvang het.

1 J. du Plessis: A History of Christian Missions in South Africa, 1965, p. 114.

2 Didache XI 5.

3 J. Jeremias: Die Briefe an Timotheus und Totus, 1965, p. 36.

4 John P. Meier: Presbyteros in the Pastoral Epistles, in: The Catholic Biblical Quarterly, Vol. 35, 1973, p. 326.

5 L. Floor: Die presbiter by Lukas en Paulus, in: Theologia Evangelica, Vol. VII, 1974, p. 94-96.

6 H. N. Ridderbos: Paulus, ontwerp van zijn theologie, 1966, p. 511.

$7 \quad \Psi \quad 69$ got.

8 Ignatius: Ad Efesos $2: 2 ; 4: 1 ; 20: 2$.

9 Strack-Billerbeck: Komm., II, p. 643; IV, p. 145 e.v.

10 J. L. Koole: Liturgie en ambt, 1949, p. 63.

11 John P. Meier: a.art., p. 327, noot 9.

12 Th. de Kruyf: De pastorale brieven, p. 66; John P. Meier, a.art., p. 326.

13 J. Reville: Les Origines de l'Epsicopat, 1894, p. 289.

141 Thess. $5: 12$; 1 Kor. $15: 10$; Gal. $4: 11$; Rom. 16:12; Fil. $2: 16$; Kol. $1: 29$; 1 Tim. 4:10; verg. Hauck, in: THWB III, p. 828, 829: hierdie w.w. is 'n aanduiding vir „Missions- und Gemeindearbeit". In 1 Thess. 5:12 gaan

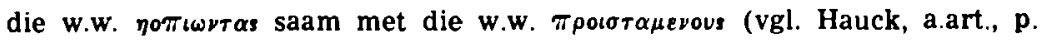
829).

15 K. H. Rengstorf: Th WB II, p. 165, noot 7.

16 J. Schniewind: Das Evangelum nach Mattheüs, 1965, p. 36: Der Gegensatz ist kein inhaltlicher"; vgl. ook p. 39. 
17 H. N. Ridderbos: De pastorale brieven 1967, p. 140.

18 W. Michaelis: Das Ältestenamt, 1953, p. 112-119.

19 C. Bouma: De brieven van den apostel Paulus aan Timotheüs en Titus, 1942, p. 190.

20 C. Bouma, a.w., p. 190.

21 Liddel and Scott: Greek-English Lexicon, 1966, p. 75: to esteem, to honor.

22 Homerus, Odisee I, 117.

23 J. Schneider, ThWB VIII, p. 179.

24 J. Héring: L' Epitre aux Hebreux, 1954, op $2: 7$.

25 Const. apost. 11, 28.

26 W. Bauer: A Greek-English Lexicon of the N.T. and other Early Christian Literature (vert. deur W. Arndt en F. Gingrich, 1968 s.v.).

27 Strack-Billerbeck III, p. 385.

28 J. Jeremias, a.w., p. 36, 37: „eine allegorisch gedeutete Tierschutzvorschrift des Alten Testaments".

29 C. Bouma, a.w., p. 192.

30 C. Spircq: Les Epitres Pasiorales, 1947, p. 179.

31 C. Bouma, a.w., p. 192. So ook E. E. Ellis: Paul's Use of the Old Testament, 1960 , p. 36 e.v.

32 C. Bouma, a.w., p. 192.

33 H. N. Ridderbos, a.w., p. 140.

34 K. L. Schmidt, in: Festgabe für Deissmann, Tübingen, 1927, p. 305 e.v. 